\section{Glyceryl Trinitrate and Angina}

Organic nitrates were introduced for the treatment of angina more than 100 years ago and have held their position almost unchallenged until the advent of the drugs causing betaadrenergic blockade. Many different nitrates in different formulations have been tried in clinicai practice, but glyceryl trinitrate is the most effective and widely used. As nitrates are powerful vasodilators, it was for long assumed that they relieved angina by increasing the blood flow to areas of the myocardium supplied by stenosed coronary arteries. In animals with a normal heart glyceryl trinitrate caused a substantial increase in coronary blood flow, but studies in patients with coronary disease have been limited by the difficulty in making satisfactory measurements of coronary blood flow.

In recent years measurements of coronary flow have been made in man by means of inert gases and radioactive tracers. None of these methods is entirely satisfactory and the results obtained are conflicting. R. Gorlin and his colleagues ${ }^{1}$ found that glyceryl trinitrate increased coronary blood flow by $63 \%$ in patients with a normal coronary vasculature but by only $16 \%$ in patients with coronary artery disease. L. Bernstein and his colleagues ${ }^{2}$ found that sublingual glyceryl trinitrate caused a decrease of $5 \%$ in coronary vascular resistance but no significant increase in coronary blood flow, because the mean aortic pressure fell by $20 \%$. The same workers injected 0.1 to $0.2 \mathrm{mg}$. of glyceryl trinitrate directly into the coronary arteries and found that flow increased by $64 \%$ in those with minimal coronary artery disease and $38 \%$ in patients with severe disease.

In contrast to the disagreement about the effects of sublingual glyceryl trinitrate on coronary blood flow there is agreement that the vasodilating action of the drug decreases both venous return and peripheral resistance. Hence it reduces the work of the left ventricle and the tension-time index by an average of $25-30 \% .{ }^{12}$

Recently R. P. Carson and co-workers ${ }^{3}$ have measured the coronary blood flow 2 and 5 minutes after a sublingual dose of $0.3 \mathrm{mg}$. of glyceryl trinitrate. Five patients with coronary artery disease showed a mean increase of flow $5 \%$ above control at 2 minutes but a decrease below control at 5 minutes. The 2-minute measurement was made during the onset of vasodilatation before the aortic pressure had fallen, while the 5-minute measurement was made during the phase of generalized vasodilatation.

Though the most recent measurements show that there is a small and transitory increase in coronary blood flow after the administration of glyceryl trinitrate, it seems most probable that its beneficial effect in angina is due to the reduction of the work of the left ventricle. Thus the antianginal action depends not on dilatation in the coronary tree but on generalized systemic vasodilatation and a reduced load on

1 Gorlin, R., Brachfeld, N., MacLeod, C., and Bopp, P., Circulation, 1959, 19, 705.

- Bernstein, L., Friesinger, G. C., Lichtlen, P. R., and Ross, R. S., Circulation, 1966, 33, 107.

- Carson, R. P., Wilson, W. S., Nemiroff, M. J., and Weber, W. J., American Heart $\mathcal{F} ., 1969,77,579$.

- Luebs, E. D., Cohen, A., Zaleski, E. J., and Bing, R. J., American Fournal of Cardiology, 1966, 17, 535 .

- Robinson, B. F., Circulation, 1967, 35, 1073.

- Epstein, S. E., and Braunwald, E., Medical Clinics of North America, 1968, 52, 1031 .

- MacAlpine R. N., Kattus, A. A., and Winfield, M. E., Circulation, $1965,31,869$. the ventricles. The point at which angina begins in an individual patient depends on the work load of the heart, ${ }^{5}$ and the beneficial effect of beta-adrenergic blocking drugs in angina also depends on reduction of left ventricular work ${ }^{6}$ -but by a different mechanism.

The ineffectiveness of glyceryl trinitrate as a coronary vasodilator is not surprising. Ischaemia itself is a potent vasodilator, but when the cause of ischaemia lies in organic narrowing of large arteries upstream, as it does in the coronary tree, it is not easy to see how a vasodilator could be much help. It is interesting to note that glyceryl trinitrate given directly into the coronary arteries had less vasodilating effect in patients with severe coronary disease, and it is probable that the increased blood flow in those with severe disease went to the less ischaemic areas of the myocardium.

The choice of drug treatment for patients with angina lies between glyceryl trinitrate and beta-adrenergic blocking drugs. Patients who have infrequent attacks of angina can often be managed with glyceryl trinitrate alone, but betaadrenergic blocking drugs should be considered for all patients who have frequent attacks of pain. These drugs have substantially improved the lot of patients with moderate or severe angina. However, many of them still require glyceryl trinitrate, though at a reduced dose. As glyceryl trinitrate and beta-blocking drugs reduce left ventricular work by a different mechanism, a synergistic action is possible. There is convincing experimental evidence that these two drugs administered together have a more favourable effect than either alone. Combined treatment should be tried for patients who still have angina at the maximum tolerated dose of propranolol. ${ }^{5}$ ?

\section{Vis Naturae}

It has been said that $90 \%$ of all the scientists who have ever lived are alive today. Without quibbling over what exactly a scientist is, we may accept this picturesque statistic as being a fair approximation to the truth. Certainly nearly all of them must have perused at some time the pages of Nature, that famous weekly periodical taking the whole of science for its province. This week, at the age of 100 , it can face its audience looking younger than ever.

Like Nature, people live today who knew a world without the motor-car yet have seen televised men walking on the moon. But with its perennial search for new frontiers, new horizons, new universes, science is a great rejuvenator. And a remarkably high proportion of the people who have so drastically transformed the world since Nature first appeared on 4 November 1869 have been contributors to its columns. If Nature herself seems a little more remote from the journal than in former times its pages do still allow the whole of her domain to be chronicled despite the later launching of many thousands of specialist periodicals. Nor is it only in the publication of original work that Nature has served the scientific community so well, for its leading articles have for many decades helped its readers to understand something of the complex relations between scientists and the nation that supports them. The B.M.F. joins a host of friends in congratulating Nature on the splendid foundation built in its first hundred years and wishing it well for the next hundred. 